\title{
KEPEMIMPINAN PEREMPUAN DI RANAH PUBLIK DALAM KAJIAN PERSPEKTIF FIQIH
}

\author{
Henderi Kusmidi \\ Institut Agama Islam Negeri Bengkulu \\ Jalan Raden Fatah, Pagar Dewa Kota Bengkulu \\ Email: hendrih034@gmail.com
}

\begin{abstract}
The existence of women in the context of strategic leadership in various lines of life including in government becomes a controversial issue among classical and contemporary scholars. Some scholars tend to allow women to be leaders in strategic positions, while some other scholars tend not to allow women to be leaders. Their views on whether or not women can become leaders are supported by each of the arguments they build. However, if each of the arguments they build is analyzed comprehensively, then it seems that the more logical and rational views of the scholars who tend to allow women to become leaders with consideration of the benefits and interpretations that will result. The implications of this are creative, innovative, constructive and gender equality perspectives in the context of leadership in all walks of life of people, nations and countries in the current era of globalization, reform and advancement of information technology. Women's leadership becomes a public issue that is always hotly discussed, even provoking polemics and debates between the pros and cons of women's leadership in the State or other public spheres. Despite the recognition of basic human rights including the right of women to be equal with men, it seems to have experienced a significant increase in various parts of the world. In terms of leadership, the position of women is still faced with the position of men. Women are considered not fit to occupy positions related to power that are considered appropriate only for men. finally to the kitchen is also often used as a tool to justify acts of injustice against women.
\end{abstract}

Keywords: Leadership, Womans, Public Area dan Islamic Law;

Abstrak: Eksistensi perempuan dalam konteks kepemimpinan strategis diberbagai lini kehidupan termasuk dalam pemerintahan menjadi permasalahan kontroversial di kalangan para ulama klasik dan kontemporer. Sebagian ulama cendrung membolehkan perempuan menjadi pemimpin dalam jabatan-jabatan strategis, sedangkan sebagian ulama yang lain cendrung tidak membolehkan perempuan menjadi pemimpin. Pandangan mereka boleh tidaknya perempuan menjadi pemimpin didukung oleh masing-masing argumentasi yang dibangunnya. Namun demikian, apabila masingmasing argumentasi yang mereka bangun itu dianalisis secara komprehensif, maka tampaknya pandangan yang lebih logis dan rasional para ulama yang cendrung membolehkan perempuan menjadi pemimpin dengan pertimbangan maslahat dan mafsadat yang akan ditimbulkannya. Implikasi dari padanya lahir pemikiran-pemikiran kreatif, inovatif, konstruktif dan perspektif kesetaraan gender laki-laki dan perempuan dalam konteks kepemimpinan di semua lini kehidupan masyarakat, bangsa dan negara di era globalisasi, reformasi dan kemajuan teknologi informasi saat ini. Kepemimpinan perempuan menjadi isu publik yang selalu hangat diperbincangkan, bahkan memancing polemik dan debat antara yang pro dan kontra terhadap kepemimpinan perempuan dalam negara atau ranah publik lainnya. Kendatipun pengakuan atas hak dasar kemanusiaan termasuk juga hak perempuan agar sejajar dengan pria tampak mengalami peningkatan yang signifikan diberbagai belahan dunia. Dalam hal kepemimpinan, posisi perempuan masih dihadapkan dengan posisi laki-laki. Perempuan dinilai belum pantas menduduki jabatan yang berhubungan dengan kekuasaan yang dianggap pantas hanya untuk laki-laki. akhirnya ke dapur juga seringkali dijadikan alat untuk membenarkan tindakan ketidakadilan terhadap kaum perempuan.

Kata Kunci: Kepemimpinan, Ranah Publik, Perempuan dan Fiqih. 
AL-IMARAH: Jurnal Pemerintahan dan Politik Islam

Vol. 5, No. 1, 2020

\section{Pendahuluan}

Perkembangan pemikiran bagi kaum perempuan dari tahun ketahun terus mengalami perkembangan yang signifikan hingga sekarang. Hal ini terlihat semakin banyaknya kaum perempuan yang ikut dalam kancah politik maupun organisasi yang dapat keterwakilan bagi kaum perempuan diberbagai jenis kegiatan dimasyarakat. Dalam kaitan ini telah banyak para perempuan berhasil meraih jabatan mulai dari yang rendah sampai posisi puncak dalam suatu lembaga, negara atau ranah publik lainnya.

Kepemimpinan perempuan dalam ranah publik atau dunia politik menjadi hal yang selalu menarik untuk dibicarakan, mulai dari meningkatnya jumlah minimum 30\% kursi di parlemen untuk perempuan, isu-isu kesetaraan gender yang mengatakan bahwa perempuan hanya menjadi pelayan seks bagi para suami mereka, dan berbagai hal lainnya yang berkaitan dengan feminisme. Fenomenafenomena inilah yang kini menghasilkan perbincangan hangat bagaimana kedudukan perempuan dalam Islam dan seperti apa pandangan Islam terhadap perempuan yang terlibat dalam politik dan bahkan menjadi pemimpin dalam sebuah perpolitikan.

Adanya pandangan bahwa perempuan di pandang lebih rendah dalam Islam menjadi sebuah perbincangan hangat pada kalangan 105 penggiat feminisme dan liberalisme. Serta adanya pendapat kaum feminis bahwa jika parlemen diisi dengan keseimbangan (equity) jumlah laki-laki dan perempuan maka akan memberikan kesejahteraan.

Sebelum membahas permasalahan kepemimpinan perempuan dalam perspeketif fiqih, dalam konteks kepemimpinan negara, masalah yang lebih mendasar dan karenanya sangat penting dibahas adalah sejauh mana Islam memberikan berbagai hak dan kewajiban kepada laki-laki dan perempuan. Dengan melakukan kajian komprehensif (istiqra) terhadap nash-nash syara' yang berhubungan hak dan kewajiban yang diberikan Islam kepada laki-laki dan perempuan, akan didapatkan kesimpulan berikut :’Bahwa Islam telah memberikan hak kepada perempuan seperti yang diberikan Islam kepada laki-laki, demikian pula Islam telah memikulkan kewajiban kepada perempuan seperti yang dipikulkan Islam kepada laki-laki, kecuali hak atau kewajiban yang dikhususkan Islam untuk perempuan, atau yang dikhususkan Islam untuk laki-laki, berdasarkan dalil-dalil syar'i.

Untuk menerangkan posisi kepemimpinan perempuan di ranah publik dalam kajian fikih kita perlu menerangkan spirit Al-qur'an dan Islam itu sendiri terhadap perempuan. Benarkah Islam menolak kepemimpinan perempuan di ranah publik? 
Dan bagaimana tinjauan para ulama dalam melihat posisi perempuan? Apakah dalam Islam tidak dibenarkan seorang perempuan menjadi pemimpin di ranah publik?

Pada dasarnya tidak ada pembedaan yang paling fundamental antara derajat perempuan dan laki-laki. Karena Alquran telah menyebutkan bahwasanya perempuan dan lakilaki setara derajatnya. Hal ini ditegaskan dalam banyak ayat Al-Qur'an antara lain terdapat dalam surat Al-Hujurat ayat 13 Allah berfirman:

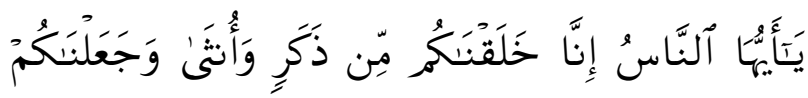

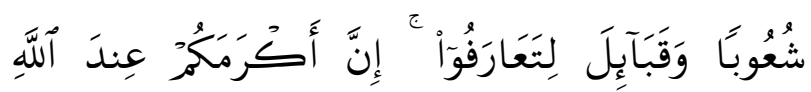

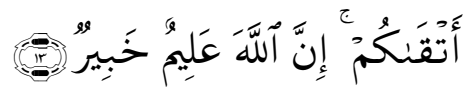

Artinya: "Hai manusia, Sesungguhnya Kami menciptakan kamu dari seorang laki-laki dan seorang perempuan dan menjadikan kamu berbangsa-bangsa dan bersuku-suku supaya kamu saling kenal-mengenal. Sesungguhnya orang yang paling mulia diantara kamu disisi Allah ialah orang yang paling taqwa diantara kamu. Sesungguhnya Allah Maha mengetahui lagi Maha Mengenal"(QS. Al-Hujurat: 13) ${ }^{1}$.

Dalam surat An-Nahl ayat 97 Allah menjelaskan pula :

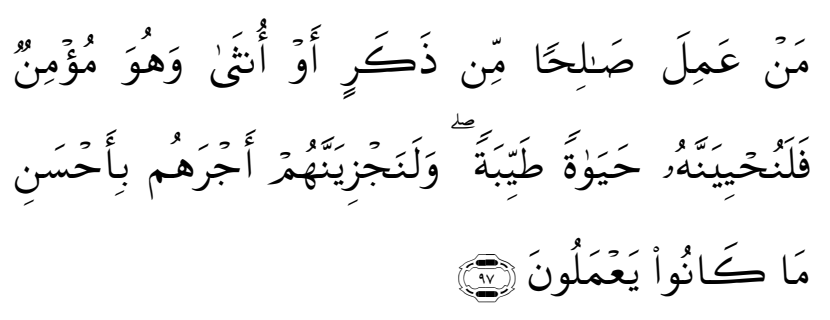

${ }^{1}$ QS. Al-Hujurat: 13
Artinya: "Barangsiapa yang mengerjakan amal saleh, baik laki-laki maupun perempuan dalam Keadaan beriman, Maka Sesungguhnya akan Kami berikan kepadanya kehidupan yang baik dan Sesungguhnya akan Kami beri Balasan kepada mereka dengan pahala yang lebih baik dari apa yang telah mereka kerjakan"(QS. AnNahl: 97) ${ }^{2}$.

Di ayat lain, perempuan dan laki-laki memiliki potensi yang sama untuk berprestasi, surah An-nisa ayat 124:

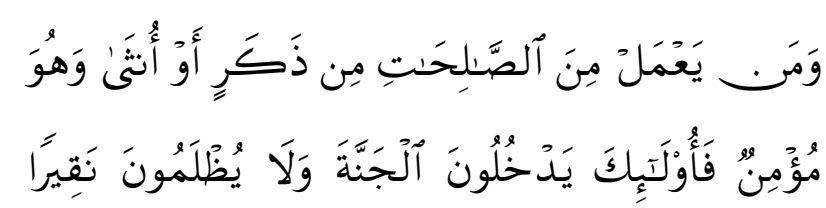

Artinya: "Barangsiapa yang mengerjakan amal-amal saleh, baik laki-laki maupun wanita sedang ia orang yang beriman, Maka mereka itu masuk ke dalam surga dan mereka tidak dianiaya walau sedikitpun"(QS. An-Nisa: 124).

Jelas sekali bahwa tidak ada pembedaan secara prinsipil antara laki-laki dan perempuan. Dalam konteks kekinian, siapapun bisa meraih kesuksesan dan cita-cita yang diharapkan. Perempuan memiliki hak yang sama di ranah publik, sebagai pejabat daerah, bahkan kalau bisa sebagai presiden. Banyak bukti negaranegara muslim yang pernah dipimpin oleh perempuan seperti Bennazir Butho di Afghanistan dan di Indonesia pun pernah. Secara de facto memang begitulah yang terjadi. Tetapi jika kita telusuri secara doktrinal ada 
AL-IMARAH: Jurnal Pemerintahan dan Politik Islam

Vol. 5, No. 1, 2020

beberapa larangan yang menyebutkan

keluar untuk berjihad dan mengurus perempuan tidak berhak menjadi pemimpin karena dikhawatirkan akan terjadi kekacauan dan ketidaksuksesan negara yang dipimpinnya.

Bagi sebagian kelompok yang melarang perempuan menjadi pemimpin, kerap kali mendasarkan pada hadis berikut:

Dalam konteks itulah, hadis Nabi

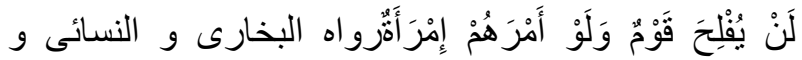
الترمذى و أحمد تولمد

Artinya: "Tidak akan sukses suatu kaum jika urusan mereka dikuasai oleh perempuan. (HR. Al-Bukhari, an-Nasa'i. AlTirmidzi, Ahmad).

Para ulama hadis memahami makna hadis di atas dengan konteks asbab alwurud. Ketika Nabi Muhammad SAW mendengar bahwa saat itu kerajaan Persia (Kisra) memimpin sebuah negara, yang membentang antara Bashrah dan Omman mendapatkan sebuah surat dakwah dari Nabi Muhammad SAW. tetapi surat tersebut disobek oleh raja tersebut. Seperti diceritakan dalam Umdatul Qari, bahwa raja tersebut pada akhirnya meninggal dan kerajaan Persia tidak memiliki keturunan yang mampu untuk melanjutkan kerajaan, kecuali seorang gadis kecil.

Tentang hadis tersebut, para ulama mengomentarinya sesuai dengan asbab alwurudnya. Imam al-Baghawi memberikan alasan bahwa seorang imam (pemimpin) harus 107 
ada sejak abad ke-15. Kepemimpinan perempuan mulai bangkit dari tidur panjang sejak isu hak asasi manusia dan persamaan gender secara lantang disuarakan oleh aktivis feminisme. Kiprah perempuan tersebut semakin menonjol pada abad ke-21. Di berbagai negara, sebagian besar perempuan mengalami perkembangan dalam berbagai sisi kehidupan atau mobilitas vertikal. Sudah banyak kaum perempuan yang dapat ruang untuk mengenyam dunia pendidikan yang sejajar dengan kaum laki-laki sehingga dapat menduduki jabatan strategis dalam ranah publik atau dunia birokrasi.

\section{Dasar Hukum Kepimpinan Dalam Islam}

Sebagai wakil Tuhan atau pemegang amanat Tuhan di bumi, tugasnya memakmurkan bumi dalam rangka menciptakan kehidupan yang sejahtera bagi seluruh umat manusia. Ini adalah teks-teks suci yang mengisyaratkan keharusan manusia untuk berpolitik. Al-Qurthubi menyatakan bahwa ayat dalam surah al-Baqarah surat kedua ayat 30 :

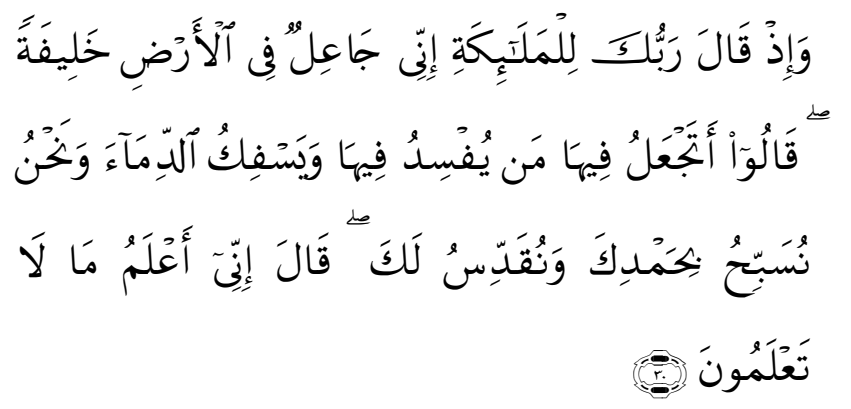

Artinya: "ingatlah ketika Tuhanmu berfirman kepada Para Malaikat: "Sesungguhnya aku hendak menjadikan seorang khalifah di muka bumi." mereka berkata: "Mengapa Engkau hendak menjadikan (khalifah) di bumi itu orang yang akan membuat kerusakan padanya dan menumpahkan darah, Padahal Kami Senantiasa bertasbih dengan memuji Engkau dan mensucikan Engkau?" Tuhan berfirman: "Sesungguhnya aku mengetahui apa yang tidak kamu ketahui."(QS. Al-Baqarah: 30) ${ }^{4}$.

Hal ini ditegaskan dalam al-Qur'an Surat AtTaubah Ayat : 71:
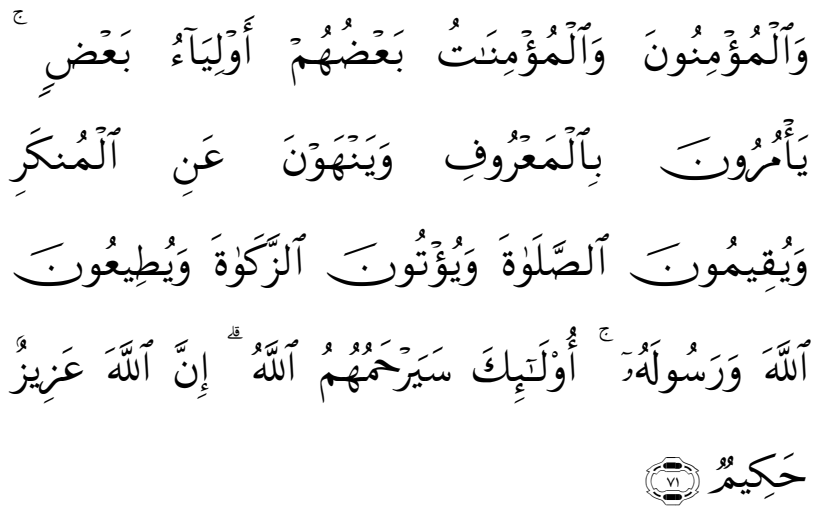

Artinya: "Dan orang-orang yang beriman, lelaki dan perempuan, sebahagian mereka (adalah) menjadi penolong bagi sebahagian yang lain. mereka menyuruh (mengerjakan) yang ma'ruf, mencegah dari yang munkar, mendirikan shalat, menunaikan zakat dan mereka taat pada Allah dan RasulNya. mereka itu akan diberi rahmat oleh Allah; Sesungguhnya Allah Maha Perkasa lagi Maha Bijaksana".(QS. At-Taubah: 71) .

Dalam ayat tersebut Allah SWT menggunakan kata "Auliyaa" (pemimpin) itu bukan hanya ditujukan kepada laki-laki saja

\footnotetext{
${ }^{4}$ QS. Al-Baqarah: 30

${ }^{5}$ QS. At-Taubah: 71
} 
AL-IMARAH: Jurnal Pemerintahan dan Politik Islam Vol. 5, No. 1, 2020

tetapi kepada keduanya (laki-laki dan perempuan) secara bersamaan. Maka berdasarkan ayat ini, perempuan bisa juga menjadi pemimpin yang penting dia mempunyai kemampuan dan memenuhi kriteria sebagai seorang pemimpin. Dalam tafsir al-maraghi dan tafsir al manar bahwa kata Auliya' mencakup wali dalam arti penolong, solidaritas dan kasih sayang. ${ }^{6}$

Maka dari surat At-Taubah Ayat 71 tersebut dapat disimpulkan bahwa Al-Qur'an tidak melarang perempuan untuk memasuki berbagai profesi sesuai dengan kompetensi dan keahliannya. Akan dalam tugasnya tetaplah memperhatikan hukum-hukum atau aturanaturan yang telah ditetapkan oleh Allah SWT dan As-Sunnah. Misalnya tidak terbengkalai urusan domestik rumah tangganya, haruslah izin dan ridho suami apabila ia sudah bersuami, agar terhindar dari efek negatif terhadap diri dan agamanya. Hanya saja dalam hal ini ulama berbeda pendapat mengenai boleh tidaknya perempuan menempati posisi top leader menjadi menteri atau kepala negara.

\section{Jumhur Ulama' berbeda} pendapat/khilafiyah boleh tidaknya perempuan menjadi hakim atau top leader. Berdasarkan Al-Quran Surat An-Nisaa' (4) ayat 34 dibawah ini :

6 Ahmad Mustafa Al Maraghi, Tafsir Al Maraghi (AL-Qahirah Mustafa Al Baby Al-Halaby Wa Aulaaduh, 1382/1963) Juz. 10 Cet. III, hal. 159, Rasyid Ridha, Tafsir Al Manar, Juz 11, tt 1375, h. 626. 109

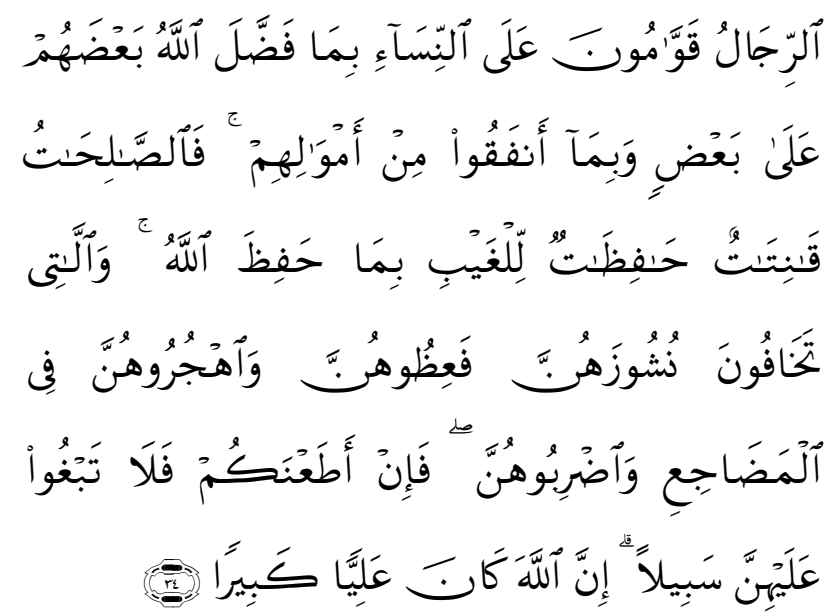

Artinya: "Kaum laki-laki itu adalah pemimpin bagi kaum wanita, oleh karena Allah telah melebihkan sebahagian mereka (lakilaki) atas sebahagian yang lain (wanita), dan karena mereka (laki-laki) telah menafkahkan sebagian dari harta mereka. sebab itu Maka wanita yang saleh, ialah yang taat kepada Allah lagi memelihara diri ketika suaminya tidak ada, oleh karena Allah telah memelihara (mereka). wanita-wanita yang kamu khawatirkan nusyuznya, Maka nasehatilah mereka dan pisahkanlah mereka di tempat tidur mereka, dan pukullah mereka. kemudian jika mereka mentaatimu, Maka janganlah kamu mencari-cari jalan untuk menyusahkannya Sesungguhnya Allah Maha Tinggi lagi Maha besar”.'(QS. An-Nisa: 34) ${ }^{7}$.

Kaidah usul fikih mengatakan:

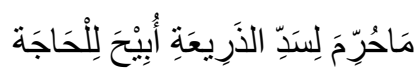

Artinya: "Sesuatu yang dilarang sebagai upaya pencegahan, dibolehkan karena adanya kebutuhan".

Perlu diketahui juga bahwa sifat kepemimpinan pada masa sekarang adalah kolektif kolegial, yaitu melibatkan banyak

\footnotetext{
${ }^{7}$ QS. An-Nisa: 34
} 
orang dalam satu pemerintahan. Sehingga seorang perempuan yang menjadi pemimpin, misalnya, tidak harus mengurus semua hal yang berkaitan dengan pemerintahan karena hal ini akan terasa sangat berat. Ia bisa secara bersama-sama bekerja dengan orang yang terlibat di dalamnya untuk mengurus kepentingan rakyat.

Yusuf Qardawi dalam fatwanya, ${ }^{8}$ mengemukakan tiga catatan mengenai penetapan hadis ini (Abi Barkah yang mengatakan bahwa tidak bahagia suatu kaum yang mengangkat pemimpin mereka perempuan), untuk dijadikan dalil penolakan kepemimpinan perempuan yakni :

1. Apakah hadis tersebut diberlakukan atas keumumannya atau terbatas pada asbabul wurudnya. Dalam pengertian bahwa Rasulullah SAW hendak menceritakan keberuntungan bangsa Persia yang menurut ketentuan hukum yang turun temurun harus mengangkat putri Kisra sebagai Kepala Pemerintahan, miskipun dikalangan bangsa itu ada orang yang lebih baik, lebih layak dan utama dari putrinya. Kebanyakan ahli ushul menetapkan bahwa yang terpakai adalah keumuman lafal bukan sebab khusus. Akan tetapi ketetapan

${ }^{8}$ Yusuf Qardawi, Fatwa-Fatwa Kontemporer Jilid III, Penerbit Gema Insani Press, Jakarta Tahun 2002, h. 543-545. atau perkataan mereka belum disepakati bahkan dari Ibnu Abbas dan Ibnu Umar tentang keharusan memelihara sebabsebab turunnya ayat. Sebab kalau tidak demikian akan terjadi kerancuan dalam memahami dan menimbulkan penafsiran buruk. Ini menunjukkan bahwa sebab turun ayat, lebih-lebih sebab wurudnya hadis wajib dijadikan acuan dan rujukan dalam memahami nash dan jangan menjadikan keumuman lafal sebagai kaidah yang baku.

2. Bahwa para ulama' ummat telah sepakat akan terlarangnya perempuan memegang kekuasaan tertinggi atau al-Imamah alUzhma sebagaimana yang termaktub dalam hadis diatas. Ketentuan ini berlaku bagi perempuan apabila ia menjadi raja atau kepala negara yang mempunyai kekuasaan mutlak terhadap kaumnya, yang segala kehendaknya harus dijalankan, semua hukumnya tidak boleh ditolak dan selain perintahnya tidak boleh dikukuhkan. Adapun keimamahan dan kekhalifahan atau apapun istilah sebagai pemegang kekuasaan tertinggi, maka masalah itu masih diperselisihkan.

Bahwa masyarakat modern dibawah sistem demokrasi, apabila memberi kedudukan umum kepada perempuan, seperti pada kementerian, perkantoran atau di dewan perwakilan, tidak bearti bahwa mereka 
menyerahkan segala urusan mereka kepada perempuan. Pada kenyataan tanggungjawab tersebut bersifat kolektif, dijalankan secara bersama-sama oleh sejumlah orang dalm lembaga terkait dan si perempuan hanya menanggung sebagian saja bersama yang lain. Selain Yusuf Qardawi menambahkan tidak semua perempuan layak menjadi pemimpin publik. Perempuan yang sibuk sebagai ibu dengan segala tugasnya tidak akan menceburkan dirinya dalam pertarungan mencalonkan diri mengemban tugas-tugas penting karena anak-anak lebih utama untuk diperhatikan.

\section{Kesimpulan}

Permasalahan perempuan menjadi pemimpin diranah publik merupakan masail alfiqh kontemporer yang menjadi kontroversial dikalangan para ahli ilmu (al-ikhtilaf wa alijtihadiyah) sejak dulu sampai saat ini. Sebagian ahli ilmu berpandangan bahwa perempuan boleh menjadi pemimpin publik dan sebagian yang lain tidak membolehkannya.

Laki-laki dan perempuan mempunyai peluang yang sama untuk melakukan kebaikan (amal salih) karena keduanya bertanggung jawab untuk memerintahkan kebajikan dan mencegah kemunkaran. Hanya saja, keterlibatan seorang perempuan dalam ranah publik (misalnya menjadi pemimpin) terlebih dahulu harus memperhatikan dan melaksanakan kewajiban yang dibebankan 111 kepadanya, misalnya mengatur urusan rumah tangga, karena bagaimanapun juga perempuan dibebani kewajiban untuk memelihara harta suaminya yang juga mencakup urusan rumah tangga, memperhatikan pendidikan anak (meskipun hal ini merupakan kewajiban suamiistri).

Hal-hal di atas perlu diperhatikan agar tidak terjadi kekacauan dalam rumah tangga yang merupakan pondasi utama untuk membangun sebuah peradaban madani. Perlu juga dipahami amal salih bukan hanya ada dalam ranah publik (menjadi pemimpin). Amal salih harus dipahami sebagai amalan yang sesuai (pantas) untuk dilakukan oleh individu berdasarkan peran dan posisi yang terdapat pada dirinya. Jika peran tersebut telah dilakukan, bolehlah seseorang melakukan pekerjaan lain dengan tetap memperhatikan aturan dan norma agama Islam.

Bahwa perempuan diperbolehkan menjadi kepala negara atau kepala pemerintahan atau pemimpin publik lainnya. Selama dalam suatu negara dimana sistem pemerintahan berdasarkan musyawarah, seorang kepala negara tidak lagi harus bekerja keras sendirian, tetapi dibantu oleh tenagatenaga ahli sesuai dengan bidang masingmasing. Karena itu tidak ada halangan bagi seorang perempuan untuk menjadi kepala negara atau kepala pemerintahan atau pemimpin publik. Yang penting adalah 
perempuan yang diangkat untuk menduduki jabatan itu, mampu, capable untuk menjalan tugas-tugasnya.

Demikianlah tulisan ini semoga bermanfaat wallaahua'lam bishshawab.

\section{Pustaka Acuan}

Al-Baghawi, Syarh As-Sunnah

Al-Qurthubi, Tafsir Al-Jami' li Ahkam alQur'an

Gibtiah, Fiqih Kontemporer, (Jakarta: Prenadamedia Group, 2016)

Ahmad Mustafa Al Maraghi, Tafsir Al Maraghi (AL-Qahirah Mustafa Al Baby Al-Halaby Wa Aulaaduh, 1382/1963) Juz. 10 Cet. III, hal. 159, Rasyid Ridha, Tafsir Al Manar, Juz 11, tt 1375

Chatibul Umam, Kajian Ayat-Ayat Al-Qur'an Tentang Wanita, (P3M IAIN Syarif Hidayatullah Jakarta, 1996)

Johari, Fikih Gus Dur (Pemeikiran dan Kontribusinya Dalam Pengembangan Hukum Islam Di Indonesia), (Jawa Timur: Pustaka Tubuireng, 2019)

Penafsiran Feminis Tentang Hak-Hak

Perempuan Dalam Islam dalam wacan Islam liberal, Cahrles Khurzman, (Jakarta: Paramadina, 2003)

Lajnah Pentashihahan Mushaf Al-Qur'an Badan Litbang dan Diklat Kementerian Agama RI, Tafsir Al-Qur'an Tematik
Edisi Revisi, (Jakaarta: Kamil Mustafa, 2014)

Musthafa al-Kin dan Musthafa al-Bugha, alFiqh al-Manhaji Ala Madzhab al-Imam asy-Syafi 'i, versi Maktabah Syamila

Imam An-Nawawi, Syarh Shahih Muslim

Buya Hamka, Tafsir al-Azhar

Yusuf Qardawi, Fatwa-Fatwa Kontemporer Jilid III, (Jakarta: Gema Insani Press, 2002)

Nasib Ar-Rifa'i, Muhammad, Kemudahan Dari Allah Ringkasan Tafsir Ibnu Katsir Jilid 1, (Depok : Gema Insani Press, 2007) 